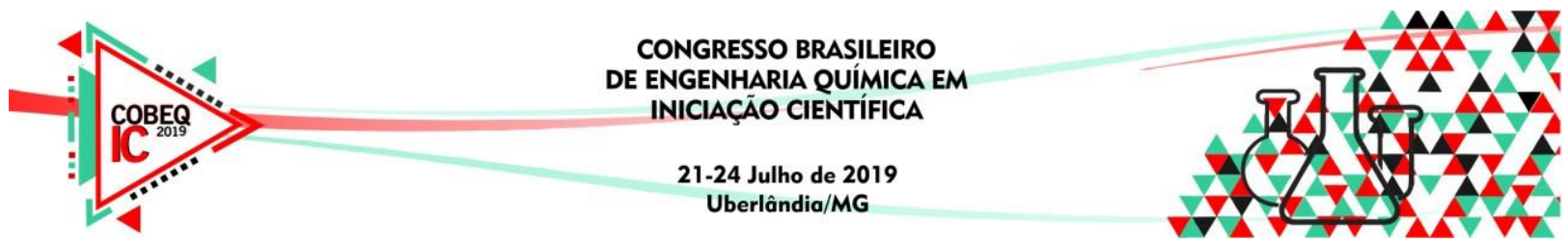

\title{
SEPARAÇÃO DO AZEÓTROPO DE EBULIÇÃO MAXÍMA ACETONA-CLOROFÓRMIO USANDO SULFÓXIDO DE METILA, ATRAVÉS DO SIMULADOR PROSIM PLUS
}

\author{
G. F. SILVA ${ }^{1}$, A.S. CHAVES 2 , C. L. ANDRADE ${ }^{3}$ e M. TELES ${ }^{1}$ \\ ${ }^{1}$ Universidade de Vassouras, Faculdade de Engenharia Química \\ E-mail para contato: guilherme.engquimica11@gmail.com
}

\begin{abstract}
RESUMO - A indústria vem passando por grandes avanços tecnológicos, na área de engenharia separação, mas mesmo assim a destilação continua a ter destaque, principalmente, por conseguir separar misturas reais, em larga escala, mas algumas, dessas combinações possuem, a mesma composição da fase líquida no ponto de ebulição, e é idêntica à do vapor em equilíbrio então não podem ser separados por uma destilação convencional, essas combinações são chamadas de misturas azeotrópicas. $\mathrm{O}$ artigo tem como objetivo a simulação do solvente sulfóxido de metila para separação da mistura azeotrópica com máximo ponto de ebulição entre acetona e clorofórmio, que é muito difícil de ser separada, com o uso do simulador ProSim Plus com auxílio do modelo termodinâmico NRTL, para fornecer dados reais e gráficos do comportamento dos componentes em relação à separação. Para conseguir uma boa separação foi necessário o uso de duas colunas de destilação onde a primeira ira quebra o, azeótropo e a segura separa solvente com o componente que ele tem mais afinidade. Através da simulação foi possível perceber que o solvente foi muito eficaz na separação do azeótropo, onde encontrado na corrente do topo da primeira coluna mais de $92 \%$ de acetona. A partir dos dados obtidos, conclui-se que o solvente é muito eficaz para essa separação e muito promissor para futuros estudos.
\end{abstract}

\section{INTRODUÇÃO}

O processo de destilação é baseado na diferença de volatilidade dos componentes a serem separados, onde a coluna de destilação separa em produto de topo e produto de fundo. Uma coluna de destilação consiste em uma série de pratos ou bandejas, comumente chamados de estágios. Os arranjos estruturais da coluna são feitos tal que o líquido que desce pela coluna tenha o maior contato possível com o vapor ascendente (REIS, 2002).

$\mathrm{Na}$ Industria química, é raro a utilização de misturas ideais em processos, normalmente as misturas não-ideais são as mais utilizadas em processos, porém algumas delas não podem ser separadas por uma destilação simples, por causa da formação do azeótropo, que é uma mistura que possui a mesma composição na fase liquida, no momento de vaporização e na fase vapor (SMITH, NESS e ABBOT,2007). Portanto é necessário, a adição de um terceiro componente, que possua um ponto de ebulição elevado, maior do que o ponto de ebulição dos componentes a serem separados, e que altere as propriedades do azeótropo para conseguir a separação. 


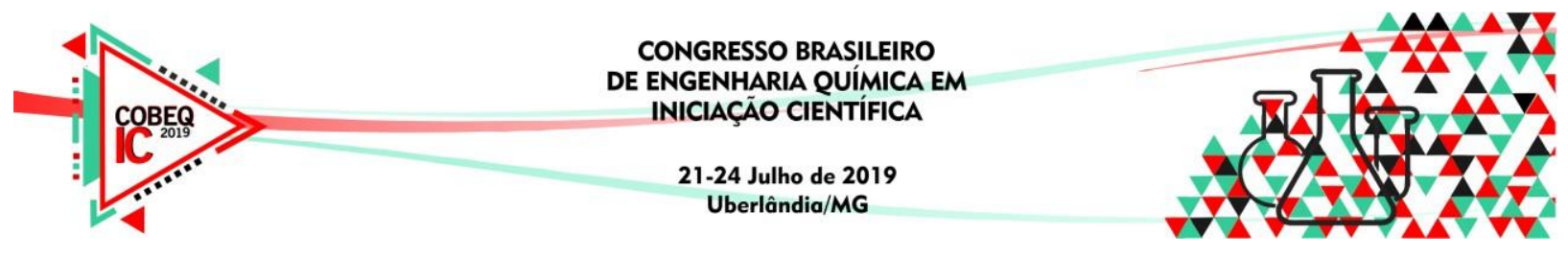

O aumento da volatilidade relativa entre os componentes de ebulição próxima causada pela introdução de um solvente seletivo, que tem uma afinidade mais forte com um tipo de componentes na mistura (LEE, 2000). Neste estudo, controlamos e otimizamos a destilação do sistema acetona-clorofórmio usando Sulfóxido dimetilo. A destilação extrativa pode ser mais eficiente energeticamente do que a separação azeotrópica, onde uma divisão de fase líquida é usada para superar os limites de destilação (LEI, LI e CHEN 2003, 121-213). Isto é especialmente verdade quando se utilizam sequências integradas termicamente (KNAPP e DOHERTY 1990, 969-984). Foi relatado que a destilação por oscilação de pressão, apesar de ser uma destilação que tem o fundamento de se obter o produto de maior teor de pureza, já que não é adicionada nenhum solvente no azeótropo, mas não é atraente para a separação do sistema acetona-clorofórmio, já que sua composição não é sensível a mudanças de pressão.

O modelo termodinâmico não aleatório de dois líquidos (NRTL) é utilizado para o processo de simulação, no ProSim Plus assim permite que o engenheiro avance e use modelos sofisticados para representar, com quase toda a complexidade, do comportamento real dos componentes e da planta, como por exemplo: projeção de reatores químicos com amplo leque de reações complexas, separadores de múltiplos estágios para extração líquido-líquido, colunas liquido- liquido-vapor de vários estágios, equipamento de tratamento solido, permutador de calor, etc..

\section{MATERIAIS E MÉTODOS}

\subsection{Descrição da Simulação}

Inicialmente para que houvesse a formação do azeótropo, houve a entrada na corrente 2 , dos dois componentes acetona e clorofórmio há $100 \mathrm{Kmol} / \mathrm{h}$ com a fração molar de 0,65 Clorofórmio e 0,35 Acetona, para assim ocorra a formação do azeótropo, há $327 \mathrm{~K}$ e com a pressão de $1.1 \mathrm{~atm}$. Após a formação do azeótropo, onde o produto obtido foi para a coluna de destilação D1, onde também foi inserido a quantidade de $75 \mathrm{Kmol} / \mathrm{h}$ do solvente Sulfóxido de metila com temperatura de $390 \mathrm{~K}$ e com a pressão de $1.1 \mathrm{~atm}$. Onde o solvente foi inserido acima do azeótropo na coluna de destilação, e abaixo de alguns pratos do topo da coluna, de forma que uma boa parte concentração do solvente ainda continue nos pratos da coluna.

Na coluna D1 onde a acetona (componente de menor ponto de ebulição) vai para a seção de decapagem enquanto, o clorofórmio vai junto com, o arrastador para a seção de retificação. (LANGSTON et al. 2005). O solvente que cai por conta da gravidade e logo entrará em contato, com o vapor que está subindo da parte inferior da coluna, em cada um dos pratos. $\mathrm{O}$ vapor que é gerado do fundo da coluna destilação, por conta do refervedor onde o vapor com maior ponto de ebulição, que fornece mais calor ao líquido e sai pelo fundo da pelo fundo da coluna D1, enquanto o vapor de menor ponto de ebulição sai no topo da coluna. A corrente inferior alimenta a coluna de destilação D2, como não há formação de azeótropo, como o clorofórmio tem menor temperatura de ebulição vai sair no topo da coluna enquanto, o solvente sai no fundo e vai para o misturador para ser reutilizado, assim como na Figura1.

Figura1. Fluxograma da separação do azeótropo acetona-clorofórmio com sulfóxido de metila, através do simulador ProSim Plus. 

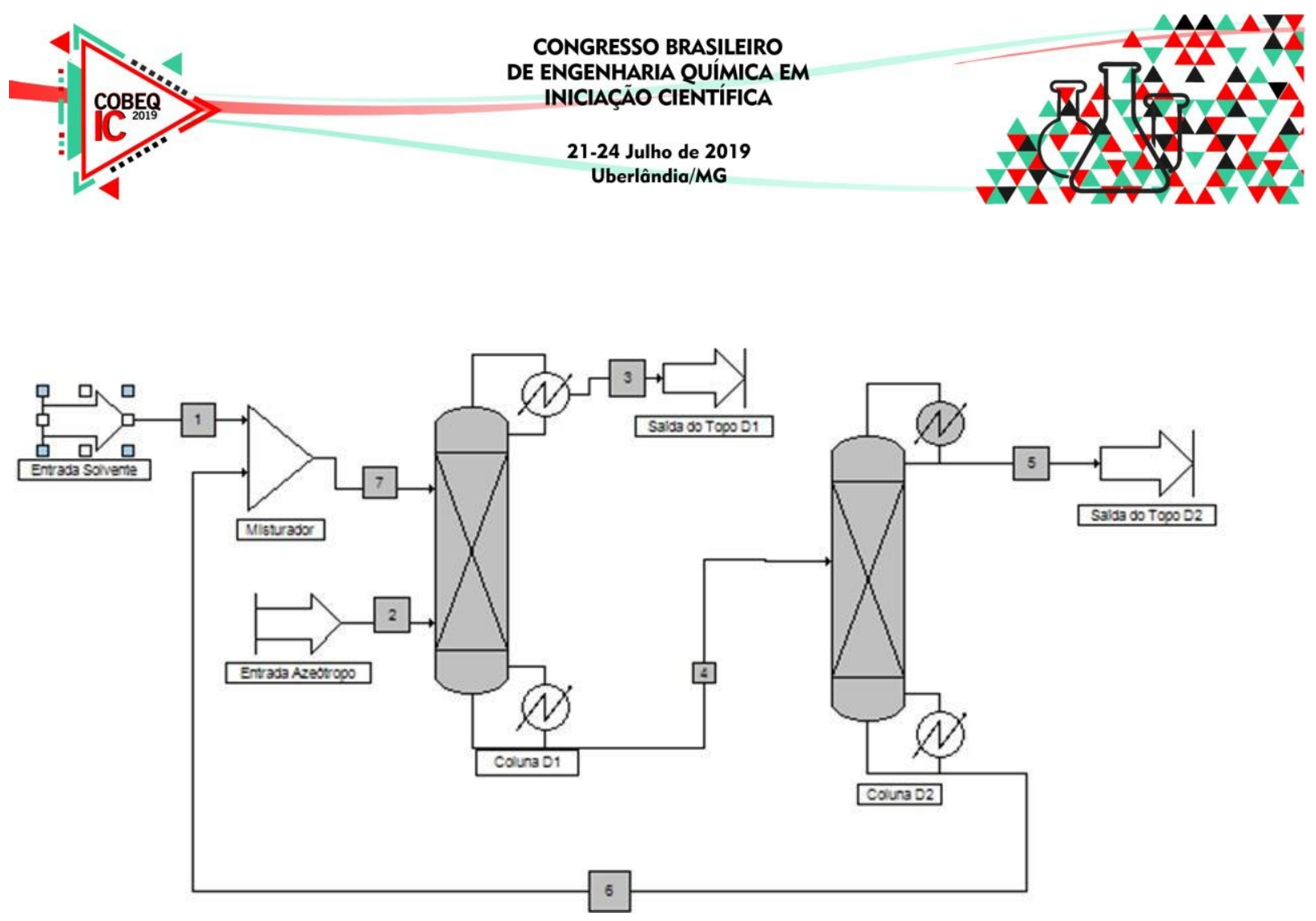

\subsection{Otimização do processo}

Para projeção do processo, foram necessários certos ajustes nos parâmetros para que o processo ocorra de forma eficiente. Foram necessários, as utilizações de muitos estágios, nas duas colunas de destilação. Na coluna D1 foram necessários 26 estágios para que houvesse a separação do azeótropo, enquanto na coluna D2 para separar o clorofórmio e o sulfóxido de metila foram necessários 10 estágios. A taxa de refluxo mínima e a taxa de fluxo mínima do solvente foram determinadas para obter o mínimo de aquecimento térmico da nova caldeira. $\mathrm{O}$ efeito do fluxo de solvente na taxa de refluxo constante e o efeito combinado do fluxo de solvente e taxa de refluxo na quantidade de clorofórmio na corrente de destilado para o sistema acetona-clorofórmio-Sulfóxido de metila e o número de bandejas utilizadas em cada alimentação assim como é ilustrado na tabela 1.

Tabela 1 - Parâmetros utilizados para otimização do processo

\begin{tabular}{|c|c|c|}
\hline Parâmetros & D1 & D2 \\
\hline $\begin{array}{c}\text { Calor do condensador } \\
\text { (Kcal/h) }\end{array}$ & 12 & 4 \\
\hline $\begin{array}{c}\text { Calor do trocador de calor } \\
\text { (Kcal/h) }\end{array}$ & 72 & 6 \\
\hline $\begin{array}{c}\text { Local da bandeja de } \\
\text { alimentação }\end{array}$ & 10 & 0,72 \\
\hline $\begin{array}{c}\text { Local da alimentação do } \\
\text { solvente }\end{array}$ & 4 & 18 \\
\hline Taxa de refluxo & 0,90 & \\
\hline
\end{tabular}




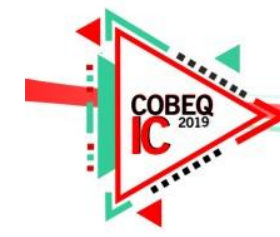

\section{RESULTADOS}

De acordo com os resultados obtidos na Tabela 2 através do ProSim Plus, é possível verificar quebra do azeótropo, quando foi obtido uma fração molar de 0,92 de acetona, no topo da coluna D1, e com fração molar de 0,028 de clorofórmio no topo e o restante do solvente, mostrando que o solvente foi muito eficaz, arrastando o clorofórmio em grandes quantidades para o fundo com uma pequena fração de acetona. Na coluna destilação D2 foi obtido uma boa separação do solvente com clorofórmio, sem a utilização de muitos pratos.

Tabela 2 - Fração dos componentes nas correntes

\begin{tabular}{|c|c|c|c|c|c|c|c|}
\hline Componentes & $\begin{array}{c}\text { Corrente } \\
1\end{array}$ & $\begin{array}{c}\text { Corrente } \\
2\end{array}$ & $\begin{array}{c}\text { Corrente } \\
3\end{array}$ & $\begin{array}{c}\text { Corrente } \\
4\end{array}$ & $\begin{array}{c}\text { Corrente } \\
5\end{array}$ & $\begin{array}{c}\text { Corrente } \\
6\end{array}$ & $\begin{array}{c}\text { Corrente } \\
7\end{array}$ \\
\hline Acetona & 0 & 0,35 & 0,92005 & 0,0020 & 0,0862 & 0,0012 & 0,00001 \\
\hline Clorofórmio & 0 & 0,65 & 0,02805 & 0,4735 & 0,9033 & 0,0047 & 0,00001 \\
\hline $\begin{array}{c}\text { Sulfóxido de } \\
\text { metila }\end{array}$ & 1 & 0 & 0,0519 & 0,5245 & 0,0105 & 0,9941 & 0,99998 \\
\hline
\end{tabular}

O objetivo de especificar os resultados encontrados, foi para mostrar as frações molares dos componentes nas correntes, como está apresentado na Tabela 2, e garantir a obtenção de produtos, com alta pureza e a minimização de poluentes.

De acordo com os resultados adquiridos, ambos componentes apresentam características muito semelhantes em relação a entalpia de vaporização, que é a quantidade de energia necessária para encontra o equilíbrio termodinâmico, com o seu próprio vapor, quando vai ocorrer a completa passagem ao estado gasoso, assim como ambas estarão passando por essa mudança com temperaturas próximas, dificulta ainda mais separação principalmente quando a formação do azeótropo, assim como é ilustrado na figura 2.

Figura 2. Gráfico da mistura da acetona e clorofórmio de acordo com entalpia de vaporização.

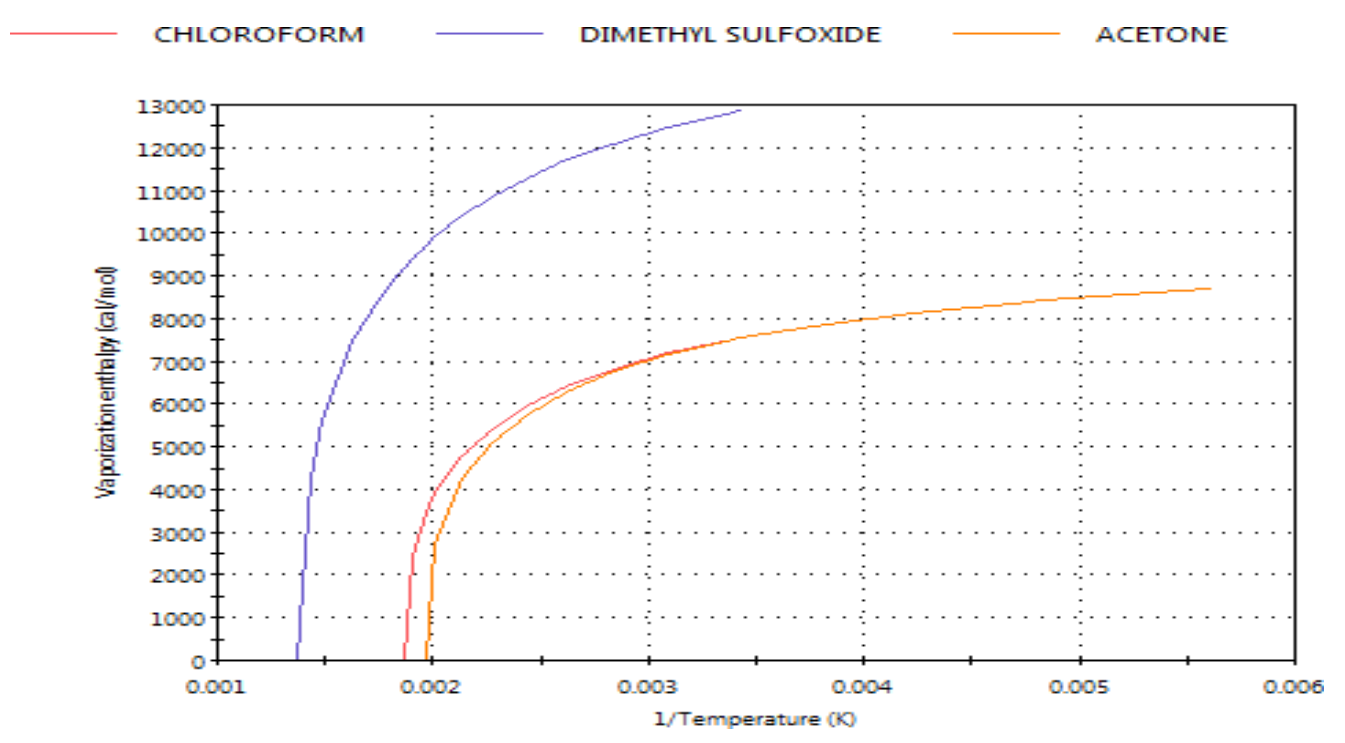




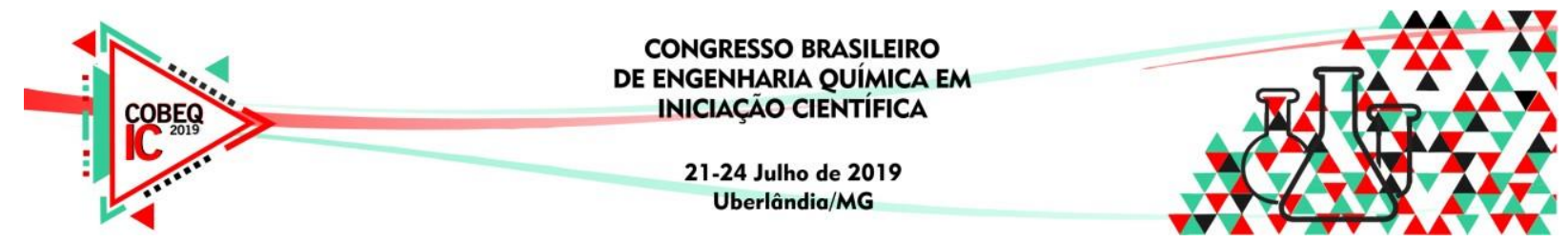

As temperaturas do topo (condensador) e do fundo (refervedor) são, as de ebulição do componente mais volátil e do componente mais pesado. As temperaturas dos outros estágios são determinadas a partir de uma interpolação linear, calculada pela pressão de saturação de cada componente na temperatura de cada prato. A razão entre esses valores e a pressão da coluna representa o valor da constante de equilíbrio para cada componente em cada prato de modo que, o número de estágios da coluna de fracionamento corresponde ao número de etapas efetivas de vaporização e condensação foram necessárias para obter um produto de topo com composição favorável. Este parâmetro pode ser expresso em termos do número de pratos. Os resultados referentes aos pratos, obtidos através da simulação, estão registrados na Figura3.

Figura 3. Dados obtidos na coluna D1, através simulador ProSim Plus.

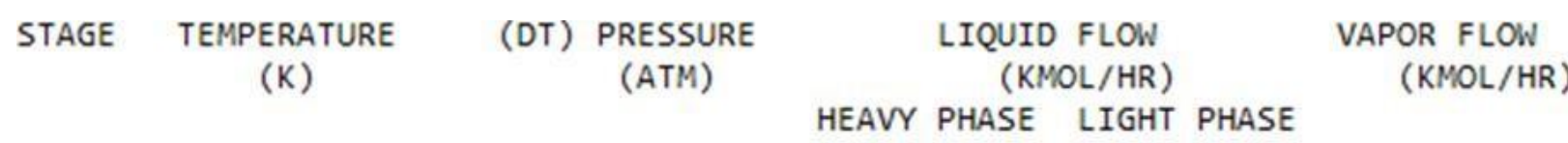

\begin{tabular}{|c|c|c|c|c|c|}
\hline \multicolumn{6}{|c|}{ CONDENSER : } \\
\hline 1 & 407.20 & $\cdots$ & 1.1000 & $0.16865 E-02$ & 1.5204 \\
\hline TOP OF & COLUMN & : & & & \\
\hline 2 & 407.35 & 0.00 & 1.1000 & $0.16867 E-02$ & 1.5221 \\
\hline 3 & 407.35 & 0.00 & 1.1000 & $0.16867 E-02$ & 1.5221 \\
\hline 4 & 407.35 & 0.05 & 1.1000 & 86.778 & 1.5221 \\
\hline 5 & 407.40 & 0.06 & 1.1000 & 86.797 & 13.298 \\
\hline 6 & 407.46 & 0.06 & 1.1000 & 86.817 & 13.317 \\
\hline 7 & 407.52 & 0.06 & 1.1000 & 86.838 & 13.337 \\
\hline 8 & 407.58 & 0.07 & 1.1000 & 86.860 & 13.358 \\
\hline 9 & 407.65 & 0.07 & 1.1000 & 86.882 & 13.380 \\
\hline 10 & 407.72 & 0.07 & 1.1000 & 86.906 & 13.403 \\
\hline 11 & 407.79 & 0.07 & 1.1000 & 86.929 & 13.426 \\
\hline 12 & 407.86 & 0.07 & 1.1000 & 86.954 & 13.450 \\
\hline 13 & 407.93 & 0.07 & 1.1000 & 86.978 & 13.474 \\
\hline 14 & 408.00 & 0.07 & 1.1000 & 87.003 & 13.499 \\
\hline 15 & 408.07 & 0.07 & 1.1000 & 87.028 & 13.524 \\
\hline 16 & 408.13 & 0.05 & 1.1000 & 87.052 & 13.548 \\
\hline 17 & 408.19 & 0.00 & 1.1000 & 87.076 & 13.573 \\
\hline 18 & 408.19 & -0.21 & 1.1000 & 87.096 & 13.596 \\
\hline 19 & 407.98 & -1.13 & 1.1000 & 87.103 & 13.616 \\
\hline 20 & 406.85 & -5.57 & 1.1000 & 87.071 & 13.623 \\
\hline 21 & 401.29 & -49.61 & 1.1000 & 87.487 & 13.591 \\
\hline 22 & 351.67 & -0.00 & 1.1000 & 173.49 & 14.007 \\
\hline 23 & 351.67 & -0.00 & 1.1000 & 173.49 & $0.63649 \mathrm{E}-02$ \\
\hline 24 & 351.67 & 0.00 & 1.1000 & 173.49 & $0.63649 \mathrm{E}-02$ \\
\hline 25 & 351.67 & 0.00 & 1.1000 & 173.49 & $0.63649 \mathrm{E}-02$ \\
\hline BOIL & : & & & & \\
\hline 26 & 351.67 & - & 1.1000 & 173.48 & $0.63649 \mathrm{E}-02$ \\
\hline
\end{tabular}




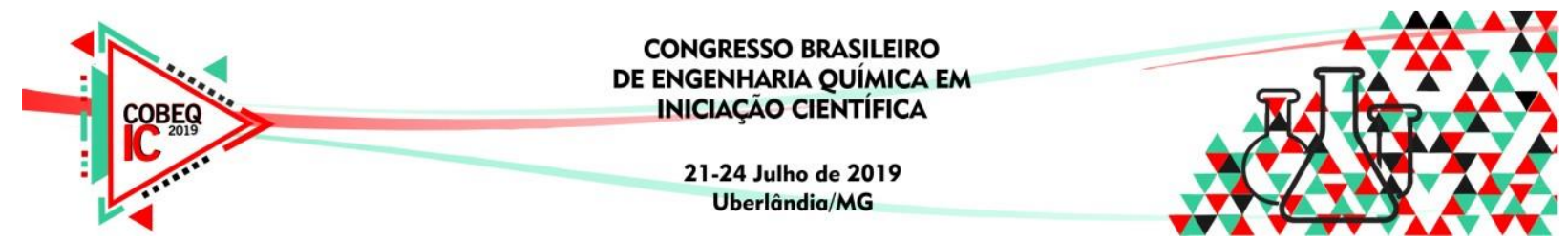

\section{DISCUSSÃO}

De acordo com os resultados obtidos constatou-se que, a destilação extrativa não pode obter uma pureza muito elevada de produto porque o sulfóxido de metila vindo da base da coluna de recuperação de solvente contém uma pequena quantidade de impureza que influencia no efeito da separação.

\section{CONCLUSÃO}

Os dados computacionais calculados, foram implementados no PROSIM Plus, e mostram que o modelo NRTL, utilizado para o cálculo dos coeficientes de atividade da fase líquida e vapor, foi bastante eficaz prevendo com boa precisão o comportamento de equilíbrio dos sistemas.

A simulação do modelo da coluna de destilação extrativa utilizada para processar a separação, da mistura acetona-clorofórmio foi obtida com sucesso, conseguindo uma boa fração do produto no topo, além do presente trabalho demostra que, o solvente sulfóxido de metila foi bastante eficaz e muito promissor para separação desse tipo de sistema.

\section{REFERÊNCIAS}

LANGSTON, P.; NIDAL, H.; SHINGFIELD, S.; WEBB, S.; Simulation and Optimisation of Extractive Distillation with Water as Solvent, Chemical Engineering and Processing: Process Intensification., 44(3), 345-51 (2007).

KNAPP, J. P; DOHERTY, M. F.; Thermal Integration of Homogeneous Azeotropic Distillation Sequences. AIChE journal 36(7),969-84 (1990)

LEE, F. M. Extraction Distillation. GTC Technology Corporation, (2000)

LEI, Z.; LI, C.; CHEN, B. Extractive Distillation: A Review, Separation and Purification Reviews, 32 (2), 121-213 (2003)

SMITH, J. M.; NESS, V. C. H.; ABBOTT, M. M.- Introdução à Termodinâmica da Engenharia Química-LTC $\quad 7^{\mathrm{a}}$ Edição (14)434-45 (2007).

REIS, M. H. M; Desenvolvimento de um programa para geração de mapas de curvas residuais e aplicação a processos de destilação azeotrópica e extrativa, 2002. 